\title{
USO DA INFOMETRIA NA IDENTIFICAÇÃO DE CLUSTERS E O DIAGRAMA MULTIDISCIPLINAR DAS PESQUISAS BRASILEIRAS SOBRE INCLUSÃO DIGITAL NA ÁREA DE EDUCAÇÃO
}

\author{
Barbara Coelho Neves ${ }^{1}$ \\ Universidade Federal da Bahia \\ barbaran@ufba.br
}

\begin{abstract}
Resumo
O artigo apresenta resultados de uma investigação sobre os fundamentos dos estudos desenvolvidos no Brasil sobre o tema inclusão digital na área de Educação. Apresenta o quadro das leis da bibliometria e o diagrama multidisciplinar das pesquisas sobre inclusão digital na Educação. Traz como objetivos discutir os fundamentos teóricos-conceituais do termo inclusão digital e apresentar alguns dos indicadores (clusters) levantados na pesquisa macro da qual este artigo é uma das partes complementares. O método utilizado é do tipo infométrico desenvolvido no Banco de Teses e Dissertações da CAPES. A coleta de dados foi realizada por meio do formulário infométrico e a análise dos dados a partir do teste sociométrico. Como resultado o artigo indica o quantitativo dos trabalhos científicos (teses e dissertações) sobre inclusão digital na Educação, os principais clusters quanto aos fundamentos teóricos e o diagrama multidisciplinar das pesquisas brasileiras sobre inclusão digital na Educação.
\end{abstract}

Palavras-chave: Inclusão Digital; Educação; Pesquisas; Estudo Infométrico; Comunicação da Informação em CT \& I.

\section{CLUSTERS AND NETWORK ANALYTICS SCIENTIFIC FOUDATION METHODOLOGY OF RESEARCH ON DIGITAL INCLUSION IN EDUCATION IN BRAZIL AREA: INFOMETRIC USE}

\begin{abstract}
The article presents the results of an investigation into the fundamentals of studies and research carried out in Brazil on the topic of digital inclusion in the field of Education. It presents the network of the analytical matrix of the methodological foundations. It aims to discuss the theoretical-conceptual foundations of the term digital inclusion and present some of the indicators (clusters) raised in the macro research of which this article is one of the complementary parts. The method used is of the infometric type developed in the CAPES Theses and Dissertations Bank. Data collection was performed using the infometric form and data analysis is performed using the sociometric test. As a result, the article indicates the quantity of scientific works (thesis and dissertations) on digital inclusion in Education, the main clusters regarding the theoretical foundations and the multidisciplinary diagram of Brazilian research on digital inclusion in Education.
\end{abstract}

Keywords: Digital inclusion; Education; Searches; Infométrico study; Communication of information on ICT.

\footnotetext{
${ }^{1}$ Professora na Universidade Federal da Bahia. Líder do Laboratório de Tecnologias Informacionais e Inclusão Sociodigital (LTI Digitl). 


\section{ARTIGO}

INOVAÇÃo

\section{INTRODUÇÃO}

Em 14 de junho de 2021 foi publicada a Lei $\mathrm{N}^{\mathrm{0}} 14.172$ que dispõe sobre a garantia do acesso à Internet, com fins educacionais, a alunos e professores da Rede Pública Estadual de ensino. Entretanto, o ministro da Economia, Paulo Guedes, afirmou que o governo cometeria crime de responsabilidade caso disponibilizasse os $\mathrm{R} \$ 3,5$ bilhões a estados e municípios para ampliar o acesso à Internet para estudantes e professores da educação pública, previstos nesta Lei 14.172/2021 (EMPRESA BRASIL DE COMUNICAÇÕES, 2021).

O governo saiu contra a lei chegando a questionar na justiça, por meio da Advocacia Geral da União (AGU), junto ao Supremo Tribunal Federal (STF) a inconstitucionalidade da matéria. Alguns parlamentares, a exemplo da deputada Professora Dorinha Seabra (DEM-TO), presidente da Comissão de Educação, disse que a postura do governo foi uma falta de respeito com o Congresso Nacional (EMPRESA BRASIL DE COMUNICAÇÕES, 2021).

O ano é 2021 e estamos falando do quesito mais básico que envolve a exclusão digital: o acesso. A situação de calamidade pública decorrente da Covid-19 trouxe à tona e escancarou a exclusão social, a desigualdade e a falta de prioridade em ciência e tecnologia no contexto da Educação.

O tema da inclusão/exclusão digital nunca deixa de ser atual e a preocupação de investigadores dos variados campos do conhecimento. Basta considerarmos que ao falarmos do par dialético no contexto digital também estamos tratando de inclusão-exclusão social. É com base nisso, que voltamos nossa investigação para um acompanhamento e análise da agenda de pesquisas sobre inclusão digital na Educação brasileira. Partimos do pressuposto que o crescente interesse dos pesquisadores da Educação pelo tema da inclusão digital está diretamente relacionado às mudanças recentes da sociedade brasileira. Respectivamente, as novas questões da agenda política brasileira constituem também um problema para o desenvolvimento da agenda de pesquisa em inclusão digital.

O que vislumbramos atualmente no âmbito da educação brasileira com relação à inclusão digital é o resultado, principalmente, das transformações que envolvem tecnologias de informação e comunicação (TIC) nesta área que procedem, de maneira mais intensa, desde o início dos anos 2000. Desse modo, observar e analisar os objetos de discussão, como são fundamentados e sob quais lentes paradigmáticas são abordados na literatura é uma maneira de reconstruir o caminho desse tema na área da Educação. Assim como também é uma forma de olhar para o futuro, aproximando-nos de elementos e aspectos do objeto que nos permitem traçar novas agendas para lidar com as transformações das relações humanas em curso. Os 
questionamentos deste estudo, que são foco neste artigo, são: qual o campo empírico (teses e dissertações) do período da primeira década dos anos 2000 no Banco de Teses e Dissertações da Capes sobre inclusão digital na Educação; e qual o enfoque dos pesquisadores dessa área que apontam como indicadores (clusters) relacionados à inclusão digital na Educação. Como principal resultado apresentamos o diagrama multidisciplinar dos principais campos que sustentam as pesquisas sobre inclusão digital na Educação.

\section{EDUCAÇÃo E INCLUSÃo DIGITAL: O CONTEXTO, A PROBLEMÁTICA E O MÉTODO}

A compreensão que se tem configura a inclusão digital como uma categoria de análise, sendo esta "para si" um objeto político. Trata-se de um discurso político materializado em programas, linhas e estratégias de ação, projetos e centros sociodigitais. Enquanto categoria, a inclusão digital vem sendo observada na Educação como política pública. O principal contexto (universo) dos sujeitos sobre os quais se desenvolvem as análises nesta área tem sido a escola.

Este artigo tem como perspectiva a ciber crítica e procurou entender políticas públicas a partir do ciclo de políticas defendido, principalmente, pelos teóricos Ball (1998). A investigação foi realizada por meio do ciclo contínuo constituído por três contextos principais:

- o contexto de influência,

- o contexto da produção, e

- o contexto da prática (BALL, 1998).

No Brasil a inclusão digital, na maioria das vezes, está associada ao discurso político apropriado pelos governos para o desenvolvimento de programas e linhas de ação. Isso quer dizer que parcelas da sociedade, a partir do discurso dos governantes, têm uma "noção" da inclusão digital, vislumbrando uma compreensão distorcida e restrita com relação ao acesso às tecnologias, sobretudo, aos computadores, mobiles e à Internet. Esse aspecto é o que Jan van Dijk (2006) chama atenção, alertando que o discurso político é muito mais poderoso e predominante quando se trata do par dialético exclusão e inclusão digital. O que observamos é que não há um conceito, mas sim uma série de elementos que apontam perspectivas que se baseiam em propostas voltadas para o acesso, treinamento ou formação. Partindo disso, localiza-se este estudo na compreensão de que se faz da inclusão digital como um contexto, movimento social, da atual demanda de formação dos indivíduos frente às tecnologias na sociedade contemporânea. 
Com base nesses aspectos, a partir de 2010 voltamos nossas pesquisas sobre inclusão digital para o mapeamento, observação e discussão, simultaneamente, ao comportamento e às tendências teóricas, metodológicas e conceituais que fundamentam o tema inclusão digital na produção da pós-graduação em Educação. Nas cercanias deste problema, o levantamento na Base de Teses e Dissertações da Capes, mantido pelo Ministério da Educação, mostrou que existe uma preocupação crescente com o tema inclusão digital nas diversas áreas do conhecimento.

\subsection{MATERIAIS E MÉTODO: O USO DA INFOMETRIA EM UM ESTUDO DA EDUCAÇÃO}

A pesquisa reúne a perspectiva de compreender a consistência do tema inclusão digital, considerando aspectos da fundamentação e pressupostos teóricos, em teses e dissertações defendidas na primeira década dos anos 2000 na área de Educação. Para tanto, utilizamos na pesquisa a infometria ${ }^{2}$, observação indireta e análise por meio da aplicação do teste sociométrico.

O estudo infométrico considera a informação registrada nos variados formatos, a exemplo do digital, do sonoro, do escrito e, em qualquer suporte material, como papel, disco, filme, banda magnética, nuvem informática, dentre outros. Talvez o maior expoente de investigação neste sentido sejam os estudos elaborados pela American Library Asociation (ALA), e cabe destacar os escritos que tratam e definem a infometria e suas leis de aplicação, a exemplo de Vanti (2005), Guedes e Borschiver (2003), Buflem (2007) e Sanz-Casado e Zorita (2014). A infometria possibilitou nesta pesquisa levantar os estudos sobre inclusão digital na área de Educação com rigor metodológico próprio, permitindo ao mesmo tempo a flexibilidade de movimentar e propor análises variadas dos resultados. Isso devido as suas saídas de dados em formato de rede.

Quanto ao desenho metodológico, trata-se de uma pesquisa com abordagem qualitativa e quantitativa, de nível analítico, adotando os métodos de infometria e bibliográfico. As técnicas adotadas para coleta de dados foram a aplicação da Lei de Zipf (frequência de palavras) com métricas e análise epistemológica e realização de observação indireta.

\footnotetext{
${ }^{2} \mathrm{~A}$ infometria é um método de pesquisa utilizado para a captura dos dados sobre esta temática. Utilizamos para a mineração o VantagePoint.
} 
De acordo com Demo (2013), a pesquisa qualitativa quer fazer jus à complexidade da realidade, curvando-se diante dela, não o contrário, sendo adequada para observar fenômenos que primam pela qualidade da análise no contexto social. Quando os métodos estão sob a luz da abordagem qualitativa estamos sinalizando que foi elaborada a captação para além da mensuração de dados quantitativos.

Os estudos métricos da informação (EMI) se desenvolveram, principalmente, na utilização de novas técnicas. Entretanto, os objetivos gerais seguem mantendo-se muito similares desde que os primeiros estudos começaram (SANZ-CASADO, 2014). Muito embora os objetivos das pesquisas sejam muito distintos e o número de trabalhos tenha apresentado um crescimento exponencial, muitos estudos desse porte se denominam genericamente como bibliometria. O gráfico a seguir apresenta a frequência anual dos trabalhos científicos na $\mathrm{Web}$ of Science (WoS), de 1971 a 2013, que se denominam com o termo bibliometria e outras métricas.

Gráfico 1: Frequência das especialidades métricas na WoS

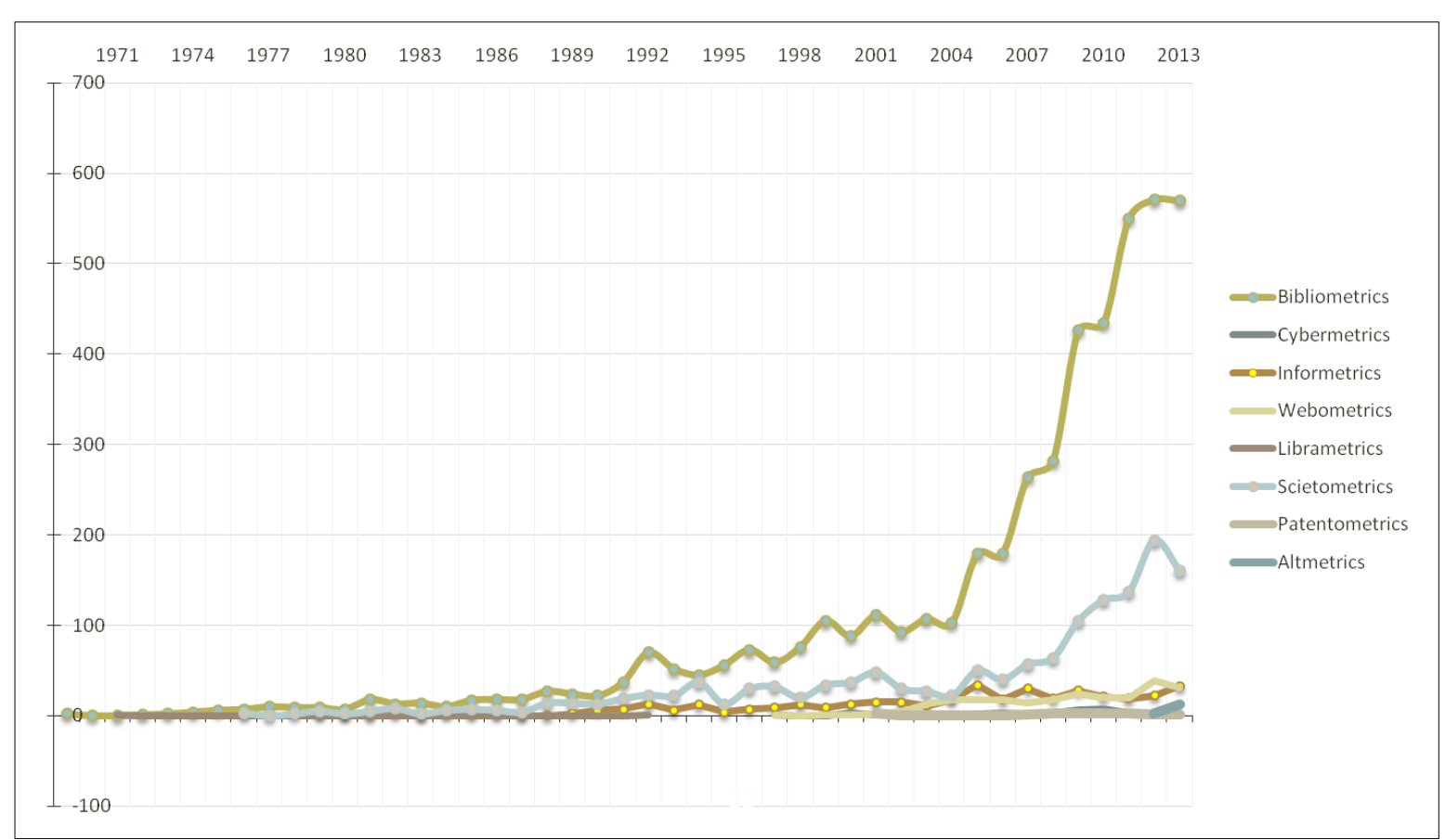

Fonte: Elaboração própria com termos adaptados da literatura científica sugerida por Sanz-Casado (2014)

Contudo, os estudos que se propõem observações dessa ordem possuem como fundamentos a Bibliografia Estatística, a Ciência da Informação e a História das Ciências. Desse modo, a infometria nos possibilitou o cruzamento de registros informacionais nesses materiais, permitindo observar, medir, indicar relevância e renovação de palavras que indicam 
a localização das respostas dos problemas sobre inclusão digital desses pesquisadores na educação.

O estudo sociométrico consiste na elaboração de perguntas, sendo realizada a tabulação das respostas e elaboração do sociograma. Essa atividade foi feita para a representação gráfica ou pictórica da tabulação sociométrica dos indicadores que cercam os estudos levantados. A técnica sociométrica e o sociograma (que é a sua representação gráfica) admitem verificar como se apresentam as relações sociais entre os pesquisadores e distinguir os líderes aceitos nos grupos (clusters).

Sua problemática está na junção da infometria (método para abordagem quantitativa) e sociometria (análise qualitativa), considerando o tema inclusão digital na educação. Assim, consequentemente, as temáticas principais que envolvem o tema em foco nas teses e dissertações, que constituem objetos de nossa análise, também perpassam as preocupações das nossas discussões. Deste modo, para compreender as incidências do tema inclusão digital na pós-graduação de educação foi necessário realizar um mapeamento dessa produção. Para traçar tal mapa, fizemos uso da aplicação de métodos estatísticos específicos, sendo a infometria associada à sociometria, entendidos como os mais adequados.

Muitos pesquisadores utilizam a infometria para explicar a crescente produção científica nas sociedades contemporâneas. A figura a seguir, mostra o alcance e influência da infometria nas outras especialidades métricas, quando a perspectiva da observação é a informação, sobretudo quando os dados são coletados em ambiente digital.

Figura 1: Relação entre as especialidades métricas na Web of Science (WoS)

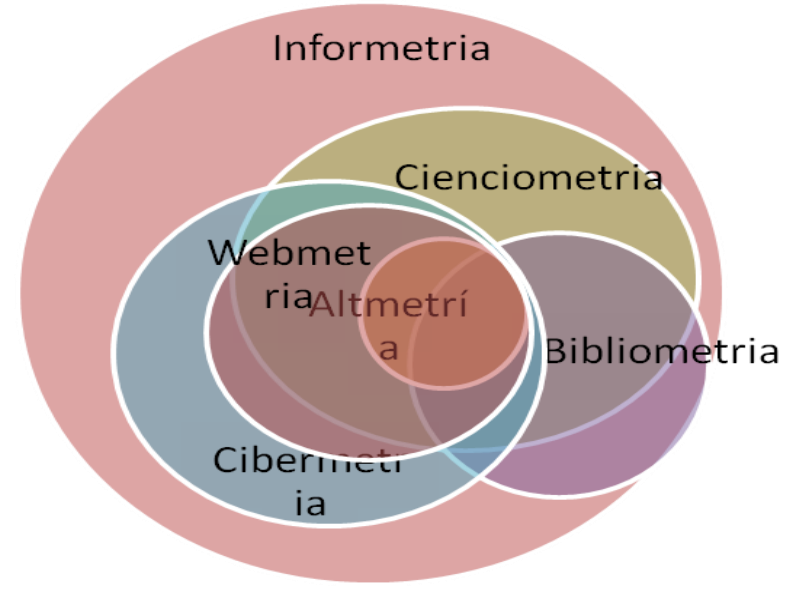

Fonte: Sanz-Casado (2014)

A infometria além de medir os fluxos de comunicações informais também tem como objeto de estudo as palavras, as informações registradas em documentos, bases de dados, home pages e redes sociais na World Wide Web (www), pois, além de medir a recuperação, a relevância e a renovação, aplicam métodos probabilísticos e linguagem voltada ao 
processamento. Desse modo, cabe explicar brevemente sobre as leis métricas, seus formuladores e em que se aplicam.

Quadro 1: Principais Leis Métricas da Ciência

\begin{tabular}{|c|c|c|c|c|}
\hline $\begin{array}{l}\text { LEIS MÉTRICAS / } \\
\text { FÓRMULAS }\end{array}$ & $\begin{array}{c}\text { SOBRE O } \\
\text { FORMULADOR }\end{array}$ & APLICAÇÃO & $\begin{array}{l}\text { EVOLUÇÃO DO } \\
\text { IMPACTO DAS } \\
\text { ESPECIALIDADES } \\
\text { MÉTRICAS }\end{array}$ & $\begin{array}{c}\text { PERPECTIVA } \\
\text { DA } \\
\text { APLICAÇÃO }\end{array}$ \\
\hline Lei de LOTKA & $\begin{array}{lrr}\text { Lotka em } & 1926 \\
\text { formulou } & \text { uma lei } \\
\text { que } & \text { permite } \\
\text { determinar } & \text { a } \\
\text { produtividade } & \\
\text { científica } & \text { dos } \\
\text { pesquisadores } & \mathrm{a} \\
\text { partir de } & \text { uma } \\
\text { equação geral, } & \text { com } \\
\text { independência } & \text { da } \\
\text { disciplina } & \\
\text { científica. } & \mathrm{O} \\
\text { número } & \text { de } \\
\text { cientistas com } & (n) \\
\text { publicações } & \text { é } \\
\text { inversamente } & \\
\text { proporcional à } & (n 2) \text {. }\end{array}$ & $\begin{array}{l}\text { A ciência avança em um } \\
\text { ritmo forte e se faz } \\
\text { necessário }\end{array}$ & $\begin{array}{l}\text { Ciência da informação } \\
\text { /Aplicações } \\
\text { matemáticas: } \\
\text { desenvolvimento de } \\
\text { modelos matemáticos / } \\
\text { Formulação de leis. }\end{array}$ & Diacrônica \\
\hline $\begin{array}{c}\text { Lei de BRADFORD } \\
(1: n 2: n 3: . . .)\end{array}$ & $\begin{array}{l}\text { Bradford em } 1934 \\
\text { propõe a ideia do } \\
\text { Catálogo coletivo } \\
\text { do conhecimento } \\
\text { humano. Observa } \\
\text { que a produtividade } \\
\text { das revistas } \\
\text { especializadas em } \\
\text { uma temática segue } \\
\text { uma progressão } \\
\text { geométrica } \\
(1: n 2: n 3: . . .) \text { Ele } \\
\text { percebeu que o } \\
\text { número de fontes } \\
\text { de informação } \\
\text { cresce rapidamente } \\
\text { e necessitam ser } \\
\text { analisadas para } \\
\text { determinar-se as } \\
\text { mais produtivas } \\
\text { e/ou as de maior } \\
\text { interesse para a } \\
\text { atualização } \\
\text { científica. }\end{array}$ & $\begin{array}{l}\text { Um pequeno número de } \\
\text { revistas é que publica a } \\
\text { maioria dos artigos } \\
\text { científicos sobre um } \\
\text { determinado tema. Essa } \\
\text { lei procura analisar a } \\
\text { dispersão da bibliografia } \\
\text { científica. } \\
\text { Indicadores de dispersão } \\
\text { das fontes de divulgação } \\
\text { da produção científica. }\end{array}$ & $\begin{array}{l}\text { Ciência da informação/ } \\
\text { Aplicações } \\
\text { matemáticas: } \\
\text { desenvolvimento de } \\
\text { modelos matemáticos / } \\
\text { formulação de leis/ } \\
\text { Estatística. }\end{array}$ & Diacrônica \\
\hline
\end{tabular}




\begin{tabular}{|c|c|c|c|c|}
\hline Lei de ZIPF & $\begin{array}{lr}\text { Zipf em } r 1935 \\
\text { analisa a frequência } \\
\text { de aparições } & \text { das } \\
\text { palavras nos textos. } \\
\text { Quando } & \text { se } \\
\text { ordenam e } & \text { se } \\
\text { multiplicam } & \text { o } \\
\text { número de ordens } \\
\text { pela frequência } \\
\text { absoluta, resulta-se } \\
\text { uma constante. }\end{array}$ & $\begin{array}{l}\text { A partir de uma lei } \\
\text { matemática é possível } \\
\text { predizer também a } \\
\text { frequência com que as } \\
\text { palavras aparecem nos } \\
\text { textos. A relevância de } \\
\text { uma palavra é } \\
\text { inversamente } \\
\text { proporcional à sua } \\
\text { frequência de aparição. } \\
\text { Estudo da frequência de } \\
\text { palavras, indicando } \\
\text { relevância. }\end{array}$ & $\begin{array}{l}\text { Ciência da informação/ } \\
\text { Aplicações } \\
\text { matemáticas: } \\
\text { Formulação de leis } \\
\text { /Linguística/ Análise de } \\
\text { conteúdo/ Filologia/ } \\
\text { Estatística } \\
\text { /Computação. }\end{array}$ & Diacrônica \\
\hline
\end{tabular}

Fonte: Elaborado pela autora

Para tanto foi desenvolvido o Quadro $1 \mathrm{com}$ as principais Leis, seus formuladores e a sua aplicação considerando aspectos evolutivos da ciência. Para este estudo, fomos influenciados pela Lei de Zipf porque o interesse principal estava na identificação da frequência de palavras e relevância. O marco temporal da pesquisa compreende de 2000 a 2013 e o levantamento no Banco de Teses e Dissertações da CAPES teve início em 2013.

\subsection{RESUltado DO ENFOQUE: OS NÚMEROS DA PESQUISA NA ÁREA DE EDUCAÇÃO}

O Banco de Teses e Dissertações da Capes apresenta o volume de 108 trabalhos sobre o tema inclusão digital na Educação. O gráfico a seguir mostra o número total de trabalhos defendidos sobre esta temática nas diversas áreas do conhecimento. Na área de Educação o tema inclusão digital também apresenta um crescimento constante até o ano de 2006. É possível perceber o início da estabilidade a partir de 2008. Este é um dos aspectos passíveis de problematização, quando levamos em consideração o crescimento da produção do tema nas demais áreas do conhecimento. 
Gráfico 1: Número de trabalhos mapeados sobre inclusão digital na educação no Banco de Teses e Dissertações da CAPES

NÚMERO DE TRABALHOS SOBRE INCLUSÃO DIGITAL NA EDUCAÇÃO

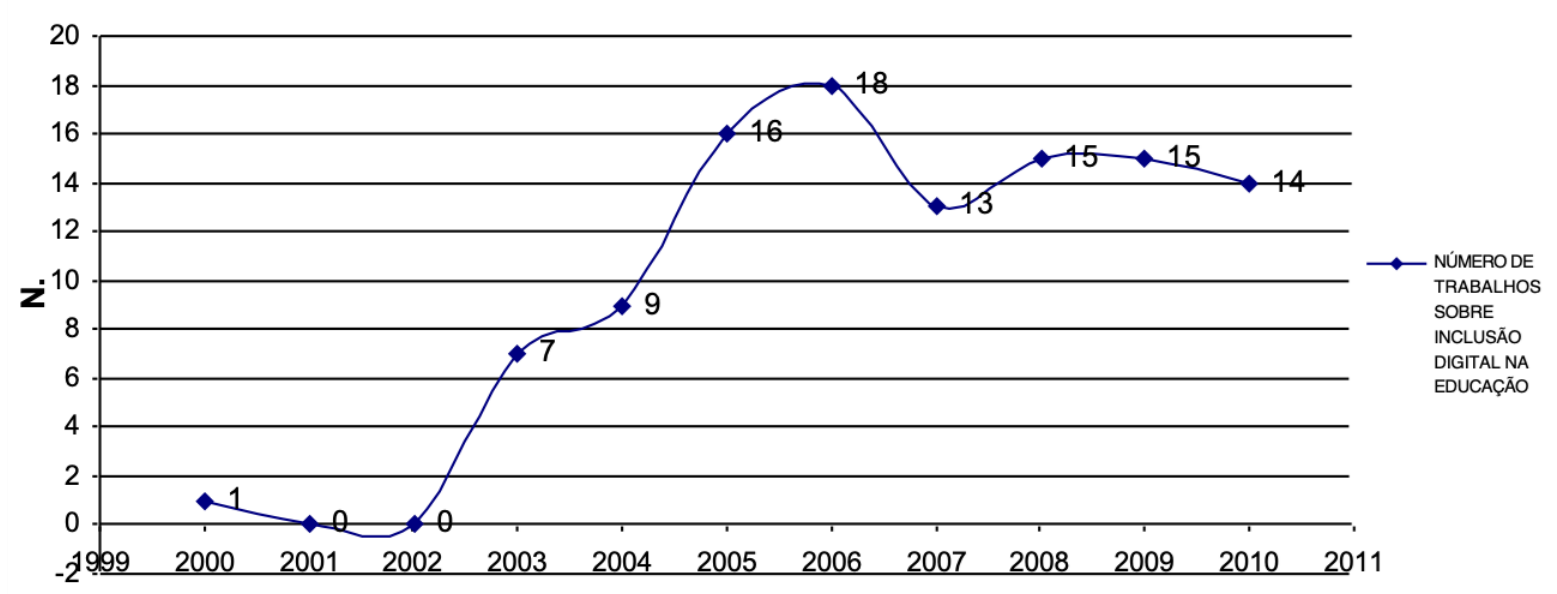

Ano de defesa

Fonte: Dados desta pesquisa

Outro ponto de problematização diz respeito à predisposição das discussões, nas variadas temáticas que estes estudos sinalizam. São temáticas voltadas para inquietações em diferentes contextos e situações-problema da qual a Educação em sua magnitude é abordada, tendo como pano de fundo ou permeando o processo o tema da inclusão digital.

\section{APROXIMAÇÕES SOBRE A INCLUSÃO DIGITAL}

Com base em autores como Warschauer $(2006,2007)$ observa-se que a educação e o aprendizado se constituem um viés preponderante na construção de uma sociedade da informação de acordo com os moldes do atual contexto socioeconômico, baseando-se nos novos meios de entretenimento, relacionamento, empregabilidade, consumo e formação de identidades.

$\mathrm{O}$ conceito de tecnologia entendido neste artigo encontra respaldo nos escritos do A. V. Pinto (2005). Nesta perspectiva, as acepções compreendem quatro:

- de caráter etimológico, atribuindo como tecnologia, teoria, ciência e estudos da técnica, as profissões, etc., logos da técnica;

- como sinônimo pura e simplesmente da técnica, know how;

- entendido como conjunto de todas as técnicas de uma sociedade, considerando seu processo histórico;

- e aquela que compreende tecnologia como ideologização da técnica. 
Para fins de fundamento deste estudo, entendemos tecnologia como o conjunto de todas as técnicas influenciadas pelo processo histórico de uma sociedade. Nesse contexto, destacamos as proposições para pensar as tecnologias de Wolton (2012), procurando diminuir a pressão da técnica sobre a comunicação. O teórico da Comunicação defende que o essencial da técnica é de outra ordem, neste caso, cultural e social, focando as relações sociais. Quem discute inclusão digital na Educação, sobretudo na pós-graduação, apresenta um entendimento sobre as TIC, sinalizando como estas podem ser usadas ou apropriadas pelos sujeitos no processo de inclusão.

Desse modo, o conceito de informação por trás das ideias defendidas neste texto é aquele discutido por Capurro e Hjorland (2007), especificamente, no contexto da recuperação da informação. Concordamos com a junção da semântica com a pragmática na recuperação da informação, proposta pelos autores, em que texto, documento, semântica e significado estão relacionados à informação. A definição de informação traz influências de Saracevic (1999, 2009) utilizado na Ciência da Informação, onde esta é compreendida como conjunto estruturado de representações mentais codificadas, socialmente contextualizadas e passíveis de serem registradas num qualquer suporte material e, portanto, comunicadas de forma assíncrona e multidirecionada (SILVA; RIBEIRO, 2008).

As discussões sobre inclusão digital na educação estão imersas em um contexto de cibercultura balizada nos trabalhos de Lévy (1994, 1997). Próximo a este debate estão os estudos de Pretto (2002) que tratam do tema formação no contexto de informática na educação. No âmbito político, a inclusão digital é um discurso potente (NEVES, 2019), pois propagam a necessidade de políticas públicas que favoreçam a difusão dessas tecnologias e no contexto da educação isso não se dá de forma diferente e o mercado tem sido o principal meio de difusão (PEIXOTO; ECHALAR, 2017).

A compreensão de ensino-aprendizagem que envolve o nosso estudo privilegia a perspectiva de mediação e interacionismo com ênfase na abordagem vigotskiana. Neste contexto destacamos os trabalhos de Duarte (2008), Luria, Leontiev e Vigotski (2005). A partir desta ótica é que nos propomos à análise crítica dos trabalhos selecionados no estudo infométrico que se realizou através do desdobramento da pesquisa.

Para analisarmos se existe uma tendência do discurso pedagógico contemporâneo (instrumental ou determinista), nos estudos que tratam do tema inclusão digital na educação, procuramos nos distanciar do debate habitual sobre tecnologias na educação. Este questionamento, por sua vez, ajuda a identificar que há uma perspectiva de inclusão digital instrumental, que vislumbra a integração das TIC na educação com foco no uso nos diferentes contextos educacionais. 
Para observar esta questão os estudos de Peixoto e Araújo (2012), de Gómez Galán (2012) e o de Sáenz del Castillo (2012) são trabalhos relevantes para nossa discussão porque tratam sobre o discurso pedagógico acerca e junto das tecnologias na educação e as correntes de investigação em tecnologia educativa. De acordo com Neves (2019), o que se vislumbra com relação à inclusão digital na Educação brasileira é o resultado das transformações que envolvem tecnologias de informação e que procedem de maneira mais intensa desde os anos finais do século XX. Segundo Neves, Freire e Suaiden (2018), determinar a exclusão (ou inclusão) depende da classe social a que o autor do discurso está se referindo.

A compreensão de inclusão que respalda a concepção de inclusão digital debatida neste artigo está balizada no conceito de integração social (CASTEL, 1998), onde os indivíduos estão incluídos e excluídos simultaneamente no mundo, no sistema, dependendo da perspectiva do objeto de desejo. Esta concepção de inclusão entende como base os vínculos relacionais que os sujeitos podem desempenhar em seus diferentes papéis.

O social não se reduz ao digital, por certo, mas ambos caminham juntos, comprometendo-se mutuamente. A inclusão digital reencontra velhos problemas no caminho da equalização de oportunidades, mesmo em países mais avançados, a ponto de ocorrer atualmente uma desconstrução da noção vulgarizada dos "nativos digitais" (THOMAS, 2011).

O crescimento econômico ao mesmo tempo em que garante a manutenção da prosperidade do "local", concorre, também, para a importação de padrões culturais do "global", mediados não somente pelos meios de comunicação de massa, como também pela indústria cultural local (FREIRE, 2014).

$\mathrm{Na}$ atualidade, os esforços dos países em desenvolvimento para a promoção da inclusão digital enfrentam a barreira da coexistência com o subdesenvolvimento econômico e acentuada desigualdade social. Para esses países, outras formas de desigualdade já existentes seriam aprofundadas por uma nova forma de exclusão materializada em um novo termo denominado de exclusão digital. Esse termo estaria ainda mais ligado à noção de exclusão pautada no que alguns autores (RIBEIRO, 1999; GARCEZ, 2007; CAZELOTO, 2008) têm chamado de "nova questão social", que, no entendimento deste texto, trata-se da pobreza historicamente conhecida incrementada pelas novas formas de acumulação de capital (NEVES; FREIRE; SUAIDEN, 2018).

Percebendo isso, entendemos a relevância de discutir estes conceitos à luz de Sorj (2006) e Sorj e Martuccelli (2008). Também entendemos necessário visitarmos as teorias que envolvem homem e sociedade e da sociedade em rede do Castells (2000). A perspectiva sociológica não constitui o eixo principal do estudo, mas certamente, lubrificam as engrenagens 
da discussão de nossa análise. Afinal, partimos da premissa de que todos os trabalhos que discutem a inclusão possuem como prerrogativa o acesso, a inserção ou emancipação dos sujeitos em um novo paradigma implementado por conta de inovações e tecnologias nas suas inter-relações sociais. Estas transformações alteram a cultura e as relações sociais, e, em um movimento dialético, estruturam e são estruturadas pela sociedade.

\section{PESQUiSAS DE INCLUSÃO Digital NA EDUCAÇÃO: CLUSTERS E O DIAGRAMA MULTIDISCIPLINAR DA INCLUSÃO DIGITAL NA ÁREA DE EDUCAÇÃO}

Acreditamos que a agenda de inclusão digital na educação está ligada às políticas públicas. Elementos dessas políticas são abstraídos para discutir questões relacionadas à infraestrutura de acesso, treinamento e formação. No Brasil, as discussões acerca da inclusão digital começam a partir da difusão do Livro Verde da Sociedade da Informação. O lançamento do Programa Sociedade da Informação no Brasil (Socinfo) teve início no ano de 1999 em Brasília-DF. A agenda de lançamentos e discussões das linhas de ação do programa se estendeu até o ano 2001 passando por várias capitais.

A partir desse marco, os ministérios do governo brasileiro, ligados a essa área, passaram a ter preocupações com relação à infraestrutura de acesso e inserção das organizações públicas e privadas na nova ordem de tecnologias de informação e comunicação mundial que se instalava. O desenvolvimento de variados programas e projetos para acesso das populações às TIC vêm sendo, desde então, oriundo de linhas de ação do Ministério do Planejamento, do Ministério das Telecomunicações, do Ministério da Ciência, Tecnologia e Inovação e do Ministério da Educação (MEC).

Desse modo, este estudo identificou que as linhas de pesquisas, que se debruçam nas discussões sobre políticas públicas de inclusão digital na Educação, têm considerado a evolução das propostas de informatização na educação. Foi possível perceber que as políticas públicas para inclusão digital na educação possuem ligação implícita com períodos e linhas de estudo, influenciando o aparecimento de pesquisas com temas neste campo.

O tema inclusão digital é tratado na educação sob várias abordagens próprias advindas de questionamentos que emergem entre sujeitos e recursos na ação educativa. $O$ estudo encontrou, a partir do mapeamento dos clusters, que o enfoque dos pesquisadores dessa área parte de preocupações relacionadas à:

- formação de professores, 
- processos educacionais,

- políticas públicas,

- currículo,

- $\quad$ acessibilidade, e

- $\quad$ educação no campo.

Estes indicadores (clusters), levantados no estudo macro, são compreendidos como categorias onde são agrupadas as principais perspectivas dos pesquisadores da área de Educação. A identificação desses clusters nos permite elaborar questionamentos, sendo um dos pontos que procuramos traduzir em questões de pesquisa, visando clarificar a agenda da inclusão digital na Educação.

Desse modo, as categorias que formam a agenda atual dos temas de preocupação das pesquisas de inclusão digital na educação tratam da:

- Formação docente como experiência de inclusão digital com ênfase na formação do professor;

- Tecnologias de informação e comunicação (TIC) nos processos educacionais com ênfase no aluno;

- Políticas públicas e educação com ênfase foco na inclusão digital;

- Currículo e inclusão digital;

- Inclusão digital e acessibilidade na educação;

- Barreiras e avanços da inclusão digital na educação no campo.

Segundo Silva, et al (2017), apesar de existir uma resistência inicial em relação ao uso de tecnologia em sala de aula da parte de muitos professores por conta de estes possuírem pouco conhecimento em relação às tecnologias digitais e requererem capacitações, o uso de tecnologia tem muito a favorecer no trabalho dos docentes, podendo otimizar muitas de suas funções e torná-las mais fáceis. Desse modo, paulatinamente, agentes envolvidos na educação, a exemplo dos gestores escolares e professores, estão se familiarizando com as tecnologias digitais e isso tem perpassado pela preocupação com a formação, os processos educacionais, o currículo, a acessibilidade e a preocupação com desafios e perspectivas nas diversas modalidades de ensino. De acordo com nosso estudo, são nesses pontos que repousam as preocupações dos pesquisadores da Educação.

Em entrevista realizada para este estudo, Pedro Demo ${ }^{3}$ acrescentou:

\footnotetext{
${ }^{3}$ Informaçäo verbal fornecida por Pedro Demo em entrevista realizada em 2013.
} 
[...] a pesquisa em educação é reconhecida como a razão fundante da vida acadêmica de seus pesquisadores. Ou seja, o investigador é por si curioso, enxergando a pesquisa como umas das principais fontes para formar seu conhecimento. Esse pesquisador deseja somar as informações adquiridas em situações anteriores com outras acessadas através dos dados fornecidos pela pesquisa. (DEMO, 2013, informação verbal).

No sentido de cooperação com outros campos, Pinheiro e Loureiro (1995), dentre vários aspectos relevantes, destacam o envolvimento dos cientistas da computação, dos cientistas sociais e da gestão nos estudos que se engajaram na área de Educação.

Esse movimento apontado pelos autores tem acontecido de maneira convergente, conforme, é possível visualizar no diagrama a seguir. Os campos que envolvem o núcleo de uma especialidade, neste caso a 'inclusão digital', se sustentam da simbiose dos estudos oriundos das áreas envolvidas, como também dos estudos desenvolvidos pelos pesquisadores da Educação, localizados nas áreas fronteiriças. Estamos entendendo como áreas fronteiriças, as regiões onde os estudos fazem intermediação entre campos de saberes científicos, materializando novos campos e subáreas que apresentam influências de áreas distintas do conhecimento. O resultado é a convergência de áreas do conhecimento para explicar um contexto, processo ou objeto científico.

Esses estudos considerados fronteiriços recebem influências direta ou indiretamente de outras áreas que fazem limites com o ‘território científico’ da inclusão digital. Desse modo, os estudos de fronteira representam um impulsionador para o crescimento da Educação como campo de estudos transdisciplinares. O diagrama da inclusão digital na educação pode ser visualizado a seguir: 
Figura 2: Diagrama multidisciplinar da inclusão digital na área de Educação

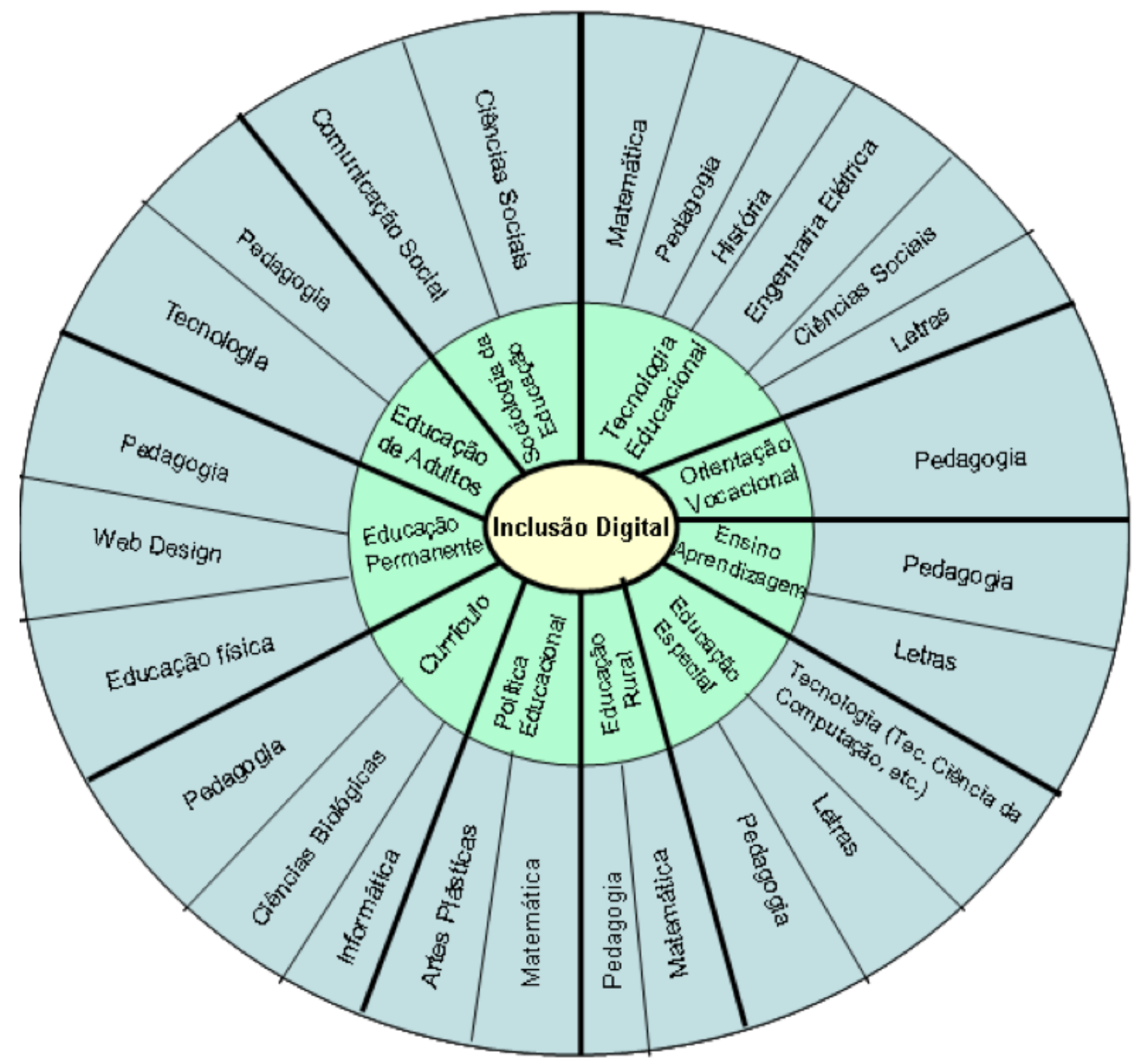

Fonte: Elaborada pela autora

Nota: Este diagrama multidisciplinar apresenta as áreas de influência no contexto do tema Inclusão digital. Refere-se às pesquisas desse tema na área de Educação no Brasil. Identificado no campo empírico 2000 a 2013.

Desde o princípio a Educação esteve aberta aos conhecimentos provenientes de outros campos científicos. De fato, a incorporação de pesquisadores de outras áreas foi fundamental para interagir e enriquecer o conteúdo. A articulação das disciplinas é a base para a multidisciplinaridade. (MORIN, 2008).

De acordo com a amostra deste estudo, diversas áreas, a exemplo de Matemática, Letras, Computação, Ciências Sociais, Informática, História, Comunicação Social, têm registrado presença nas questões elaboradas para discutir a inclusão digital nas subáreas da Educação. Estas subáreas compreendem: Tecnologia Educacional, Ensino Aprendizagem, Orientação vocacional, Educação Especial, Educação Rural, Política Educacional, Currículo, 
Educação Permanente, Educação de Adultos e Sociologia da Educação. Essa sinalização não é feita por acaso; podemos observar o Diagrama Multidisciplinar da Inclusão Digital na Educação, na Figura 2, para perceber as inúmeras áreas que influenciam nestas subáreas.

A convergência de áreas do conhecimento, especialmente no que se refere àquelas que operam com o mesmo objeto de estudo é uma circunstância habitual e, possibilitam o crescimento e afirmação dos respectivos campos conceituais. Porém, essa contribuição fica, muitas vezes, restrita às áreas fronteiriças, ou entre os campos que fazem parte do mesmo grupo de ciências, e que convergem graças à experiência do pesquisador frente ao objeto acadêmico que está sendo observado.

\section{CONSIDERAÇÕES FINAIS}

A pesquisa que empreendemos vislumbra a oportunidade de se estudar com maior profundidade o tema da inclusão digital na Educação. Para tanto, além do levantamento da produção acadêmica no Banco de Teses e Dissertações da Capes, procuramos associar métodos específicos de pesquisa e análise de dados consolidados na Ciência da Informação, mas pouco explorados na área de Educação. Compreender, como os pesquisadores dessa área constroem suas perguntas de pesquisa e abordam o tema inclusão digital, representa um problema relevante para se traçar uma agenda de pesquisa sobre tal temática.

Os resultados apresentados neste artigo fazem parte de uma pesquisa mais ampla e profunda, pois mapeia de maneira exaustiva o Banco de Teses e Dissertações da Capes com o intuito de analisar como a inclusão digital vem sendo estudada e fundamentada, a partir dos anos 2000, no que concerne a sua agenda de pesquisa para a educação brasileira.

Destacamos que o quantitativo de trabalhos defendidos sobre o tema nas diversas áreas do conhecimento continua em crescimento. Em comparação, no mesmo período, na área de Educação, é possível perceber uma estabilidade no cálculo da idade média da produção (defesas sobre o tema).

Conclui-se que o tema inclusão digital teve seu auge de discussão na primeira metade da década dos anos 2000 e no final da primeira década se consolidou, e, vem se modificando, quanto ao perfil dos autores, bases metodológicas utilizadas e territórios explorados. Portanto, a análise aqui proposta revela a importância do acompanhamento da produção técnicometodológica da inclusão digital na Educação pela comunidade acadêmica, pois enriquece o 


\section{ARTIGO}

INOVAÇÃO

processo de internacionalização almejado pela revista, ao mesmo tempo que a inserção de técnicas dos estudos do tipo bibliométricos.

\section{REFERÊNCIAS}

BALL, S.J. Big policies/small world: an introduction to international perspectives in education policy. Comparative Education, Penn State, v. 34, n. 2, p. 119-130. 1998.

CAPURRO, R.; HJØRLAND, B. The concept of information. Annual Review of Information Science and Technology, v. 37, p. 343-411, 2007.

CASTEL. R. As metamorfoses da questão social: uma crônica do salário. Trad. Iraci Poleti. Petrópolis: Vozes, 1998.

CASTELLS, M. A sociedade em rede. Trad. de Roneide Venancio Majer. São Paulo, Paz e Terra, 2000.

DEMO, Pedro. Charme da exclusão social. Campinas: Autores Associados, 2002.

DIJK, J. A. G. M. Van. The Network society: social aspects of new media. 2 ed. London: Sage Publication, 2006. 292p.

DUARTE. N. Sociedade do conhecimento ou sociedade das ilusões?. Campinas: Autores Associados, 2008.

EMPRESA BRASIL DE COMUNICAÇÃO (EBC). Ministro defende veto a Lei que amplia acesso à internet a estudantes. Agência Brasil. 2021. Disponível em:

https://www.ebc.com.br/. Acesso em: 10 ago. 2021.

FREIRE, Isa Maria. Sobre a temática "responsabilidade social" na literatura da Ciência da Informação indexada pela Brapci. Logeion, Brasília, v. 1, n. 1, p. 59-76, 2014.

GUEDES, V. L. S.; BORSCHIVER, S. Bibliometria: uma ferramenta estatística para a gestão da informação e do conhecimento, em sistemas de informação, de comunicação e de avaliação científica e tecnológica. Rio de Janeiro, 2003.

LÉVY, P. Cyberculture. Paris, Éditions Odile Jacob, 1997.eq

LÉVY, P. L'intelligence colletive. Pour une anthopologie du cyberspace. Paris, Éditions La Découvert, 1994.

LURIA, A. R.; LEONTIEV, A.N.; VYGOTSKY, L.S. Psicologia e pedagogia: bases psicológicas da aprendizagem e do desenvolvimento. São Paulo: Centauro, 2005. 
INOVAÇÃo

NEVES, B. C. Center for information management and intelligence of the School of Public Legal Defense of the State of Bahia. Biblios (Lima), v. 45, p. 64-69, 2012.

NEVES, B. C.; FREIRE, I.M.; SUAIDEN, E.J. Conscientização da metamorfose: discussão sobre os conceitos de inclusão e integração no âmbito da inclusão sociodigital. Comunicações. V.25, n.2, 2018. Disponível em: DOI http://dx.doi.org/10.15600/2238121X/comunicacoes.v25n2p3-27 . Acesso em: 02 de 2020.

NEVES, B.C. Inclusão digital na educação: ciborgues, hackers e políticas públicas. Curitiba: CRV, 2019.

PEIXOTO, J.; ECHALAR, A. D. L. F. Tensões que marcam a inclusão digital por meio da educação no contexto de políticas neoliberais. Revista Educativa - Revista de Educação, Goiânia, v. 20, n. 3, p. 507-526, dez. 2017. ISSN 1983-7771. Disponível em: $<$ http://seer.pucgoias.edu.br/index.php/educativa/article/view/6836 $>$. Acesso em: 25 maio 2021.

PINTO, Á. V. O conceito de tecnologia. Rio de Janeiro: Contraponto, v.1, 2005.

PRETTO, N. L. Formação de professores exige rede! Revista Brasileira de Educação, Rio de Janeiro, n.20, 2002.

RIBEIRO, M. Exclusão: problematização do conceito. Educação e Pesquisa, São Paulo, v. 25, n.1, p.23-49, jan-jun. 1999.

SANZ-CASADO, E.; ZORITA, C. G. Evolution of Epistemological Foundations of Metric Information Studies. 4. Encontro Brasileiro de Bibliometria e Cientometria. Anais..., Recife, Edufpe, 2014.

SARACEVIC, T. Information science. In: Marcia J. Bates and Mary Niles Maack (Eds.) Encyclopedia of Library and Information Science. New York: Taylor \& Francis, 2009.

SILVA, A. M.; RIBEIRO, F. Das ciências documentais à ciência da informação: ensaio epistemológico para um novo modelo curricular. Porto: Afrontamento, 2008.

SILVA, I. N. et al. Inclusão digital em escolas públicas através de tecnologias inovadoras de baixo custo no ensino de disciplinas STEM. Novas Tecnologias na Educação, V. 15 No 2, dezembro, 2017.

SORJ, B. A nova sociedade brasileira. 3 ed. Rio de Janeiro: Jorge Zahar, 2006.

VANTI, N. A. P.. Os links e os estudos webométricos. Ciência da Informação, Brasília, v. 34, n. 1, p. 78-88, jan./abr. 2005.

WARSCHAUER, M. Learning the digital age. Educational Leaderschip, London, v.63, n.4, dec.2005-jan 2006, p. 34-38. 


\section{ARTIGO}

- INOVAÇÃo

WARSCHAUER, M. Laptops and literacy: learning in the wireless classroom. New York: Teaches College Press, 2007.

WOLTON, D. Internet, et après? Paris: Flamarion, 2012.

THOMAS, M. Technology, Education, and the Discourse of the Digital Native: Between evangelists and dissenters. In:Thomas, M (Ed) Deconstructing Digital atives: Young people, technology and the new literacies. London: Routledge, p. 1-11, 2011. 